\title{
Identifying Patients at Risk for High-Grade Intra-
}

\section{Abdominal Hypertension following Trauma}

\section{Laparotomy}

Steven G. Strang ${ }^{1 \mathrm{~A}}$, Diederik L. Van Imhoff ${ }^{1 \mathrm{~A}}$, Esther M.M. Van Lieshout ${ }^{1}$, Scott K.

D’Amours ${ }^{2}$, Oscar J.F. Van Waes ${ }^{1}$

${ }^{1}$ Erasmus MC, University Medical Center Rotterdam, Department of Surgery-Traumatology,

Rotterdam, the Netherlands

${ }^{2}$ Department of Trauma, Liverpool Hospital and the University of New South Wales, Sydney,

New South Wales, Australia

${ }^{\text {A }}$ Both authors contributed equally to this work

Address for correspondence:

O.J.F. Van Waes, MD

Erasmus MC, University Medical Center Rotterdam

Department of Surgery-Traumatology

Room H-822k, P.O. Box 2040

3000 CA Rotterdam

The Netherlands

Tel: +31 107031050

Fax: +31 107032396

E-mail: o.vanwaes@erasmusmc.nl 


\section{Abstract}

Background: Abdominal Compartment Syndrome (ACS) is an uncommon but deleterious complication after trauma laparotomy. Early recognition of patients at risk of developing ACS is crucial for their outcome. The aim of this study was to compare the characteristics of patients who developed high-grade intra-abdominal hypertension (IAH) (i.e., grade III or IV; intra-abdominal pressure, IAP > $20 \mathrm{mmHg}$ ) following an injury-related laparotomy versus those who did not (i.e., IAP $\leq 20 \mathrm{mmHg}$ ).

Methods: A retrospective analysis of consecutive trauma patients admitted to a level 1 trauma center in Australia between January 1, 1995 and January 31, 2010 was performed. A comparison was made between characteristics of patients who developed high-grade IAH following trauma laparotomy versus those who did not.

Results: A total of 567 patients (median age 31 years) were included in this study. Of these patients $10.2 \%$ (58/567) developed high-grade IAH of which $51.7 \%$ (30/58) developed ACS. Patients with high-grade IAH were older $(\mathrm{p}<0.001)$, had a higher Injury Severity Score $(\mathrm{p}<0.001)$, larger base deficit $(\mathrm{p}<0.001)$ and lower temperature at admission $(\mathrm{p}=0.011)$. In the first 24 hours of admission, patients with high-grade IAH received larger volumes of crystalloids $(\mathrm{p}<0.001)$, larger volumes of colloids $(\mathrm{p}<0.001)$ and more units of packed red blood cells $(\mathrm{p}<0.001)$. Following surgery prolonged prothrombin $(\mathrm{p}<0.001)$ and partial thromboplastin times $(\mathrm{p}<0.001)$ were seen. The patients with high-grade IAH suffered higher mortality rates $(25.9 \%(15 / 58)$ vs. $12.2 \%(62 / 509) ; \mathrm{p}=0.012)$.

Conclusion: Of all patients who underwent a trauma laparotomy, 10.2\% developed highgrade IAH, which increases the risk of mortality. Patients with acidosis, coagulopathy, and hypothermia were especially at risk. In these patients, the abdomen should be left open until adequate resuscitation has been achieved, allowing for definitive surgery. 
Level of Evidence: This is a level III retrospective study

Keywords: Trauma, Laparotomy, Intra-Abdominal Pressure, Intra-Abdominal Hypertension, Abdominal Compartment Syndrome 


\section{Background}

Trauma is the leading cause of death in people aged 1 to 44 years and exsanguination is a common cause of death (1). Such active bleeding focus is frequently located intraabdominally (2). In patients presenting to hospital following severe injury, hemodynamic instability or acute abdominal findings can mandate laparotomy. Laparotomy in this setting may be lifesaving.

Despite improved survival following laparotomy, patients are still at risk of developing abdominal compartment syndrome (ACS) $(3,4)$. ACS is a syndrome of intra-abdominal hypertension (IAH) with new onset or worsening organ failure. The World Society of the Abdominal Compartment Syndrome (WSACS) defines ACS as an intra-abdominal pressure (IAP) $>20 \mathrm{mmHg}$ with clinical signs of new organ failure, such as renal failure or increasing ventilation difficulties $(5,6)$. ACS is termed primary when it originates from intra-abdominal pathology, secondary when originating from an extra-abdominal source and tertiary or recurrent when ACS occurs in an already decompressed abdomen (7). WSACS defines IAH as an IAP $\geq 12 \mathrm{mmHg}$ and introduced a IAH grading system for increasing severity with grades from I to IV(8). Grade I (IAP 12-15 mmHg) and II (IAP 16-20 mmHg) are referred to as low-grade IAH and Grade III (IAP 21-25 mmHg) and IV (IAP> $25 \mathrm{mmHg}$ ) are referred to as high-grade IAH. IAH and ACS result from decreased abdominal wall compliance and/or increased intra-abdominal volumes (fluid, edema).

ACS in isolation is generally treated through medical means or by decompressing the abdomen. The resulting laparostomy can be kept open for several days to a week using a temporary abdominal closure technique (TAC) (9). Surgeons can consider using TAC 
following trauma laparotomy when a patient is likely to develop IAH or ACS. However, a prolonged open abdomen is associated with higher morbidity including intra-abdominal infections, sepsis, anastomotic leakage, intestinal fistulae and sepsis (10-13). Knowledge of specific risk factors for IAH or ACS following trauma laparotomy may help the surgeon to mitigate these risks and improve outcomes. The aim of this study was to compare characteristics of patients who developed high-grade IAH following trauma laparotomy versus those patients who did not. 


\section{Methods}

A retrospective analysis was performed on trauma patients who underwent trauma laparotomy in a level I trauma center in Australia. This trauma center serves over 1 million inhabitants and admits more than 350 trauma patients annually with an injury severity score (ISS) greater than 15 (14). Data of admitted trauma patients were prospectively collected by trained trauma nurse coordinators (15). This registry has been recording more than 154 different variables for seriously injured patients, and has done so since 1994.

Consecutive trauma patients who underwent trauma laparotomy within 24 hours of admission between January 1, 1995 and January 31, 2010 were included. Trauma registry data were collected as was information from clinical notes. This study was approved by the hospital's Human Research Ethics Committee.

Data collection included patient demographics, IAP's, information on organ function and diagnosis of ACS, abdominal decompression, ISS, shock, mechanism of injury, temperature on admission, lactate, base deficit, $\mathrm{pH}$, hemoglobin level, resuscitation fluid(s), resuscitation volume, survival, and ICU/hospital lengths of stay. IAH and ACS were defined in accordance with the WSACS guidelines (6). Data were complete, unless specified differently in the Table footnotes.

Data were analyzed using SPSS version 16 (SPSS Inc. Released 2007. SPSS for Windows, Version 16.0. Chicago, SPSS Inc.). Youden index was analysed using MedCalc version 14.10.2 (MedCalc Software, Ostend, Belgium). Inspecting frequency histograms and Q-Q plots revealed that the majority of continuous variables deviated from a standard normal distribution. Therefore, all continuous variables were regarded as non-normal and are shown as median values with first and third quartiles. Differences between patients with versus without high-grade IAH were tested using a Mann-Whitney U-test (continuous variable), a 
Fisher's exact test or Chi-squared test (categorical variables). Binary logistic regression analysis was performed in order to determine the strength of the association between covariates (independent variables) and the IAH grade (dependent variable; high-grade versus no high-grade IAH ). Odds Ratio are presented with 95\% confidence intervals. The HosmerLemeshow test statistic (Chi-squared value) with corresponding p-value is given as measure of model calibration, and the area under the Receiver Operating Characteristic (ROC) curve is provided as measure of discriminatory power. The Youden Index $(\mathrm{J}=\max$ (sensitivity + specificity - 1)), representing the maximum vertical distance between the ROC curve and the diagonal line, was calculated in order to determine at which value of the evaluated variable the sum of sensitivity and specificity had the highest value. The Youden index was shown with its $95 \%$ confidence interval following bootstrapping (1,000 replicates and 900 randomnumber seeds). For continuous variables the optimal threshold value is also shown. P-values $<0.05$ were considered statistically significant. 


\section{Results}

Over a 16-year period 583 trauma patients presented to the emergency department and underwent trauma laparotomy. Of these patients, 16 underwent trauma laparotomy more than 24 hours following admission or were pregnant and therefore were not included in the study.

Baseline characteristics of the 567 included patients are shown in Table 1. Patients had a median age of 31 years, the majority of these patients were male, two-thirds sustained blunt injury and less than half had circulatory shock (defined by SBP $<90 \mathrm{mmHg}$ ) at the time of presentation to the emergency department. Of the included patients $10.2 \%(58 / 567)$ developed an IAP > $20 \mathrm{mmHg}$, of which 51.7\% (30/58) developed ACS. In order to compare characteristics and potential risk factors for ACS following trauma laparotomy, patients were divided into two separate groups; patients with an IAP $\leq 20 \mathrm{mmHg}$ (no high-grade IAH, $\mathrm{N}=509$ ) and patients with an IAP $>20 \mathrm{mmHg}$ (high-grade IAH, N=58). The patients with high-grade IAH following trauma laparotomy were older $(\mathrm{p}<0.001)$, had a higher injury severity score (ISS; $(\mathrm{p}<0.001)$ and were more frequently in circulatory shock at presentation $(\mathrm{p}<0.001)$. Blunt abdominal trauma mechanisms were relatively more frequently seen in the high-grade IAH group than penetrating trauma mechanisms $(\mathrm{p}=0.012)$. Of the baseline characteristics investigated, higher age, higher ISS, being presented in circulatory shock, or having sustained blunt trauma increased the odds of developing a high-grade IAH (Odds Ratio, OR, 1.05, 1.03, 4.51, and 2.38, respectively).

Of the 567 laparotomies performed, immediate abdominal closure was undertaken in 479 (84.5\%) patients; the abdomen was not immediately closed in 80 patients. The remaining 8 patients died during surgery or the data set could not be completed (Figure 1). Following 
immediate abdominal closure, $7.1 \%$ (34/479) developed high-grade IAH, of which $41.2 \%$ (14/34) developed ACS. In the group where the abdomen was not closed immediately, $30.0 \%$ (24/80) developed high-grade IAH, of this group 62.5\% (15/24) still developed ACS either before or after delayed abdominal closure. In 20.8\% (5/24) of patients who did not have immediate abdominal closure and developed high-grade IAH, delayed primary closure of the abdomen was not possible. Four of these five patients died $(80.0 \%$; 95\% Confidence Interval, CI $38-96 \%)$, which was substantially more than the $31.6 \%$ of patients $(6 / 19 ; 95 \%$ CI $15-54 \%)$ in whom early delayed primary closure was possible $(\mathrm{p}=0.150)$.

A total of 57 relaparotomies was performed in the 479 patients in whom the abdomen was directly closed; 38 in the group without high-grade IAH $(8.5 \% ; 38 / 445)$ and 19 in the highgrade IAH group $(55.9 \% ; 19 / 34)$. No significant association was found with mortality; mortality rates were $12.3 \%(7 / 57)$ in patients who had a relaparotomy versus $7.3 \%(31 / 422)$ in patients who did not $(\mathrm{p}=0.300)$.

Physiologic and fluid resuscitation parameters were identified as possible risk factors for high-grade IAH by determining values of these parameters at admission and approximately 6 hours after surgery (Table 2). Patients who developed high-grade IAH following trauma laparotomy more frequently presented with hypothermia $(\mathrm{p}=0.011)$ and acidosis as demonstrated by a lower $\mathrm{pH}(\mathrm{p}<0.001)$, higher levels of lactate $(\mathrm{p}=0.013)$, and a larger base deficit $(p<0.001)$ than those in whom IAP remained $\leq 20 \mathrm{mmHg}$. Following laparotomy, these differences remained, except for hypothermia. On the other hand coagulopathy, expressed as a prolonged Prothrombin Time $(\mathrm{PT})(\mathrm{p}<0.001)$ or Partial Thromboplastin Time $(\mathrm{PTT})$ $(\mathrm{p}<0.001)$, was seen following trauma laparotomy in patients with high-grade IAH. Logistic regression analysis showed that hypothermia at admission (OR 0.74) and presence of acidosis 
and coagulopathy (PTT) at six hours after trauma laparotomy (OR 0.05 and 1.01, respectively) significantly increased the odds of developing high-grade IAH.

Patients with high-grade IAH following laparotomy received larger volumes of resuscitation fluid in the emergency department $(\mathrm{p}=0.001)$ and during the first 24 hours following admission $(\mathrm{p}<0.001)$ compared to patients without high-grade IAH (Table 3). Even though this was mainly due to crystalloid volumes administered in the first 24 hours of admission (6.0L vs. $4.2 \mathrm{~L} ; \mathrm{p}<0.001)$, patients also received larger volumes of colloid resuscitation in the first 24 hours of admission (2.5 vs. 1.5L, $\mathrm{p}<0.001)$. Patients with high-grade IAH also received more blood transfusions (17 vs. 2 units of packed red cells, $\mathrm{p}<0.001)$. The total resuscitation volume as well as the volume of crystalloids and colloids given in the first 24 hours all increased the odds of developing high-grade IAH (OR 1.17-1.21).

Patients with high-grade IAH following trauma laparotomy had worse outcomes than patients without high-grade IAH with a higher mortality rate $(25.9 \%(15 / 58)$ vs. $12.2 \%(62 / 509)$; $\mathrm{p}=0.012$ ), a longer median ICU length of stay ( 15 days vs. 1 day; $\mathrm{p}<0.001$ ), and a longer median hospital length of stay ( 44 days vs. 9 days; $p<0.001$ ) (Table 4). 


\section{Discussion}

This analysis demonstrates associations between the development of high-grade IAH following trauma laparotomy and presence of acidosis, coagulopathy, and hypothermia. Coagulopathy is often associated with acidosis and hypothermia and these factors combined are associated with injury severity (ISS) (16). More severely injured patients often require larger volumes of resuscitation fluids which is a known risk factor for IAH (17). Moreover, a direct relation between acidosis (univariate analysis), hypothermia (multivariable analysis) and IAH has been confirmed $(18,19)$.

Acidosis, coagulopathy, and hypothermia could not be confirmed as independent risk factors for high-grade IAH by multivariable analysis. Nevertheless, it does suggests that the typical patient who gets a damage control laparotomy, is also at risk for high-grade IAH. Leaving the abdomen open after a damage control laparotomy and delaying abdominal closure until coagulopathy, acidosis and hypothermia are corrected seems to be a good strategy.

Patients arriving to the emergency department in circulatory shock, were twice as likely to develop high-grade IAH following trauma laparotomy. Crystalloid fluid resuscitation is a common first choice in emergency departments, but excessive use of it is a known risk factor for ACS (20). In this study, crystalloid resuscitation volumes were significantly higher in patients with high-grade IAH following trauma laparotomy. This is in concordance with the view that excessive crystalloid use is a risk factor for ACS following trauma laparotomy too. Over the studied period, no trend was observed in used volumes of crystalloid resuscitation fluid. High-grade IAH patients also received significantly larger colloid resuscitation volumes, total resuscitation volumes and more units of packed red blood cells over the first 24 hours following admission. More recently, a benefit for colloid resuscitation (including 
hydroxyethyl starches; HES) over crystalloid resuscitation with respect to days free from mechanical ventilation, vasopressor therapy and 90-day mortality has been suggested (21). Two other studies have advocated against the use of HES-based resuscitation, as HES-based resuscitation was associated with higher 90-day mortality rates in sepsis patients and an increased need for renal-replacement therapy in an ICU population $(22,23)$. Our analysis could not confirm a benefit for colloid resuscitation with respect to the development of highgrade IAH.

In the data presented, there are increased mortality rates associated with IAH grade and the use of open abdomen treatment. Mortality was highest in patients in whom delayed primary abdominal closure was not possible (80\%; 4 out of 5). Inability to close the abdomen is known to be related to high morbidity and mortality (24). The presented data show significantly higher mortality following inability to close the abdomen than in patients in whom delayed abdominal closure was possible. Although the populations were too small in this analysis to attain statistical significance, it may suggest that open abdomen is an unfavourable condition. Moreover, open abdomen does not necessarily prevent ACS from occurring. In the 24 patients that developed high-grade IAH after open abdomen treatment, 15 patients still developed ACS. ACS developed during open abdomen treatment in seven of these 15 patients $(46.7 \%)$ and after abdominal closure it developed in six patients $(6 / 15$; $40.0 \%$ ). For the remaining two patients, it is unknown at what moment exactly the ACS was diagnosed.

The results of the current study indicated a lower mortality in patients with an open abdomen without high-grade IAH $(14.7 \% ; 5 / 34)$ than in patients with a closed abdomen and high-grade IAH $(37.5 \% ; 21 / 56 ; \mathrm{p}=0.034)$. This is likely attributable to a more severe injury in the former group. Although the patients with an open abdomen without high-grade IAH were significantly younger (median age 33 vs 52 years; $p=0.001$ ), they were more frequently in 
circulatory shock at presentation $(83.9 \%(47 / 56)$ versus $58.8 \%(20 / 34) ; \mathrm{p}=0.018)$ and had a higher median ISS (38 versus $29 ; \mathrm{p}=0.048$ ) than patient with a closed abdomen and highgrade IAH. Resuscitation (volume and composition), acidosis, coagulopathy, and hypothermia was not statistically significantly different between these two groups (data not shown).

Severely injured patients and patients in circulatory shock in whom trauma laparotomy is performed for blunt abdominal injury and who subsequently develop coagulopathy, hypothermia, or acidosis are at risk for ACS. These patient may benefit from open abdomen treatment, even though this treatment is associated with high morbidity and mortality $(25,26)$. Recently developed (vacuum assisted) temporary abdominal closure devices seem to improve patient outcome (27). Nevertheless, open abdomen treatment should be avoided when the development of high-grade IAH is unlikely. When open abdomen treatment is applied, abdominal closure should be aimed at as soon as possible after internal stabilization (preferably within a week).

Our study possesses several limitations. Given that ACS is a relative rare finding, patients who only developed high-grade IAH were interpreted as patients with a high risk for developing ACS. As mentioned, the number of patients who actually developed ACS was low. Even though ACS is relatively rare, its impact on patient outcome is very large, therefore early recognition of patients at risk is of developing ACS is important. Another limitation is the retrospective design of this study. Even though a retrospective design is unfavourable, it made inclusion of large patient numbers possible. The large population of patients that underwent trauma laparotomy is the main novelty of this study, it concerns the largest series published until now. Lastly, none of the identified characteristics of patients at risk for ACS could be confirmed with multivariable analysis. The multivariable analysis was hampered by the extent of redundancy and collinearity between the covariates. This makes interpreting the 
findings more difficult. For example, the high mortality in patients in whom delayed abdominal closure was not possible, may also be a result of selection bias and injury severity. Larger (prospective) studies are needed to quantify the relative contribution of the demonstrated characteristics to the overall risk of high-grade IAH in patients following trauma laparotomy.

In conclusion, patients in need of a damage control laparotomy who develop acidosis, coagulopathy, and hypothermia, are at risk of IAH and ACS. At the time of trauma laparotomy in patients with these ACS risk factors, temporary abdominal closure with primary closure as early as possible, seems a good strategy. 
Table 1 - Patient demographics for the overall population as well as separated for the groups with an IAP $\leq \mathbf{2 0} \mathbf{m m H g}$ and $>20 \mathrm{mmHg}$

\begin{tabular}{|c|c|c|c|c|c|c|c|c|}
\hline Variable & $\begin{array}{l}\text { Overall } \\
(\mathrm{N}=567)\end{array}$ & $\begin{array}{l}\text { IAP } \leq 20 \\
(N=509)\end{array}$ & $\begin{array}{c}\text { IAP > } 20 \\
(N=58)\end{array}$ & P-value & $\begin{array}{c}\text { OR } \\
(95 \% \mathrm{CI})\end{array}$ & $\begin{array}{c}\text { H-L Test } \\
\text { (Chi-square) }\end{array}$ & $\mathbf{A U C}$ & $\begin{array}{c}\text { Youden Index } \\
\text { (95\% CI; threshold) }\end{array}$ \\
\hline$\overline{\text { Age (year) }}$ & $31(23-44)$ & $30(22-42)$ & $50(34-65)$ & $<0.001$ & $1.05(1.04-1.07)$ & $7.83(0.450)$ & 0.75 & $0.39(0.26-0.47 ;>35)$ \\
\hline Males & $452(79.7 \%)$ & $404(79.4 \%)$ & $48(82.8 \%)$ & $0.680^{\mathrm{B}}$ & $1.25(0.61-2.55)^{\mathrm{D}}$ & N.A. & $(0.52)^{\mathrm{G}}$ & 0.03 (0.00-0.10; N.A.) \\
\hline ISS & $21(13-34)$ & $20(11-34)$ & $34(22-44)$ & $<0.001$ & $1.03(1.01-1.04)$ & $24.82(0.002)$ & 0.70 & $0.35(0.25-0.46 ;>25)$ \\
\hline Circulatory shock ${ }^{\mathrm{A}}$ & $220(38.8 \%)$ & $179(35.2 \%)$ & $41(70.7 \%)$ & $<0.001^{\mathrm{C}}$ & $4.51(2.46-8.27)^{\mathrm{E}}$ & N.A. & $(0.68)$ & 0.36 (0.23-0.47; N.A.) \\
\hline Blunt Injury & $374(66.0 \%)$ & $327(64.2 \%)$ & $47(81.0 \%)$ & $0.012^{\mathrm{B}}$ & $2.38(1.20-4.70)^{F}$ & N.A. & $(0.58)$ & 0.17 (0.04-0.26; N.A.) \\
\hline Penetrating Injury & $193(34.0 \%)$ & $182(35.8 \%)$ & $11(19.0 \%)$ & & & & & \\
\hline
\end{tabular}

ACS, Abdominal Compartment Syndrome; AUC, Area Under the Receiver Operating Characteristic (ROC) curve. H-L, Hosmer-Lemeshow goodness of fit test; IAP, Intra-Abdominal Pressure (mmHg); ISS, Injury Severity Score; N.A., Not Applicable; OR, Odds Ratio.

Descriptive data are shown as median with the $\mathrm{P}_{25}-\mathrm{P}_{75}$ between brackets or as number with the percentage between brackets.

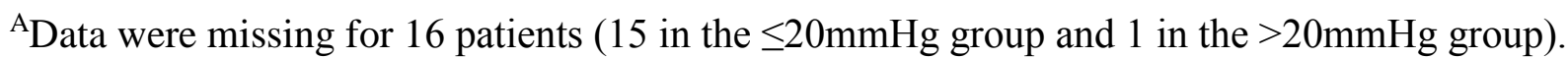

P-values are calculated using Mann-Whitney U-test, ${ }^{\mathrm{B}}$ Fisher's exact test, or ${ }^{\mathrm{C}}$ Chi-squared test . 
Odds Ratios are determined using a binary logistic regression and are expressed for the comparison of ${ }^{\mathrm{D}}$ males versus females as reference category; ${ }^{\mathrm{E}}$ Unstable versus stable; ${ }^{\mathrm{F}} \mathrm{Blunt}$ versus penetrating trauma. Odds Ratios are given with the $95 \%$ confidence interval (CI) between brackets. The H-L statistic is given with the p-value between brackets. Statistically significant OR's and H-L values are shown in boldface. ${ }^{\text {G}}$ The AUC values for these binary variables are based on only a single value of sensitivity and specificity. The Youden Index is shown with the 95\% $\mathrm{CI}$ and (for continuous variables) the threshold value between brackets. For categorical variables, the threshold value is not applicable (N.A). 
Table 2 - Physiologic variables separated for the groups with an IAP $\leq 20 \mathrm{mmHg}$ and $>20 \mathrm{mmHg}$

\begin{tabular}{|c|c|c|c|c|c|c|c|c|}
\hline & $\begin{array}{l}\text { Overall } \\
(\mathrm{N}=567)\end{array}$ & $\begin{array}{l}\text { IAP } \leq 20 \\
(\mathrm{~N}=509)\end{array}$ & $\begin{array}{l}\text { IAP > 20 } \\
(\mathrm{N}=58)\end{array}$ & P-value & $\begin{array}{c}\text { OR } \\
(95 \% \mathrm{CI})\end{array}$ & $\begin{array}{c}\text { H-L Test } \\
\text { (Chi-square) }\end{array}$ & AUC & $\begin{array}{c}\text { Youden Index } \\
\text { (95\% CI; threshold) }\end{array}$ \\
\hline \multicolumn{9}{|l|}{ At admission } \\
\hline Temperature $\left({ }^{\circ} \mathrm{C}\right)^{\mathrm{A}}$ & $36.2(35.4-36.8)$ & $36.2(35.5-36.8)$ & $35.8(34.9-36.7)$ & 0.011 & $0.74(0.57-.96)$ & $6.44(0.598)$ & 0.62 & $0.19(0.09-0.27 ; \leq 35.9)$ \\
\hline Lactate $(\mathrm{mmol} / \mathrm{L})^{\mathrm{B}}$ & $2.6(1.7-5.4)$ & $2.1(1.7-4.1)$ & $7.4(3.0-12.3)$ & 0.013 & $1.33(1.08-1.64)$ & $10.86(0.210)$ & 0.75 & $0.53(0.25-0.75 ;>4.8)$ \\
\hline Base deficit $(\mathrm{mmol} / \mathrm{L})^{\mathrm{C}}$ & $5.0(2.0-10.0)$ & $5.0(1.8-8.0)$ & $10.0(6.0-18.0)$ & $<0.001$ & $1.11(1.06-1.16)$ & $11.30(0.185)$ & 0.73 & $0.40(0.23-0.49) ; \geq 6.0)$ \\
\hline $\mathrm{pH}^{\mathrm{D}}$ & $7.29(7.19-7.34)$ & $7.30(7.22-7.35)$ & $7.17(7.03-7.27)$ & $<0.001$ & $0.02(0.003 .-0.12)$ & $12.68(0.080)$ & 0.73 & $0.43(0.28-0.56 ; \leq 7.19)$ \\
\hline $\mathrm{Hb}(\mathrm{mmol} / \mathrm{L})^{\mathrm{E}}$ & $7.5(6.1-8.6)$ & $7.6(6.2-8.8)$ & $7.1(5.3-8.0)$ & 0.050 & $0.87(0.73-1.04)$ & $4.53(0.807)$ & 0.60 & $0.19(0.08-0.27 ; \leq 7.6)$ \\
\hline \multicolumn{9}{|l|}{ At 6 hours after surgery } \\
\hline Temperature $\left({ }^{\circ} \mathrm{C}\right)^{\mathrm{A}}$ & $37.1(36.6-37.5)$ & $37.1(36.6-37.5)$ & $37.0(36.4-37.4)$ & 0.176 & $1.04(0.97-1.12)$ & $10.18(0.252)$ & 0.56 & $0.12(0.06-0.17 ; \leq 35.8)$ \\
\hline Lactate $(\mathrm{mmol} / \mathrm{L})^{\mathrm{B}}$ & $3.7(2.1-5.6)$ & $2.9(1.9-4.5)$ & $6.2(3.4-8.3)$ & 0.005 & $1.54(1.16-2.04)$ & $14.30(0.074)$ & 0.74 & $0.44(0.24-0.58 ;>6.1)$ \\
\hline Base Deficit $(\mathrm{mmol} / \mathrm{L})^{\mathrm{C}}$ & $5.0(3.0-9.0)$ & $5.0(2.2-8.9)$ & $8.0(5.0-12.7)$ & $<0.001$ & $1.08(1.03-1.13)$ & $10.02(0.264)$ & 0.66 & $0.26(0.08-0.33 ; \geq 4.1)$ \\
\hline $\mathrm{pH}^{\mathrm{D}}$ & $7.30(7.21-7.35)$ & $7.30(7.23-7.36)$ & $7.23(7.12-7.31)$ & $<0.001$ & $0.05(0.01-0.34)$ & $13.68(0.091)$ & 0.66 & $0.28(0.14-0.41 ; \leq 7.23)$ \\
\hline PT (seconds) ${ }^{\mathrm{F}}$ & $13.9(12.7-16.1)$ & $13.7(12.6-15.7)$ & $15.6(13.9-20.1)$ & $<0.001$ & N.D. & N.D. & N.D. & $0.34(0.20-0.44 ;>14.7)$ \\
\hline PTT (seconds) ${ }^{\mathrm{G}}$ & $33(29-43)$ & $32(28-40)$ & $41(34-95)$ & $<0.001$ & $1.01(1.01-1.02)$ & $25.30(0.001)$ & 0.68 & $0.35(0.21-0.44 ;>33)$ \\
\hline $\mathrm{Hb}(\mathrm{mmol} / \mathrm{L})^{\mathrm{E}}$ & $6.7(5.7-7.8)$ & $6.8(5.9-7.9)$ & $6.2(5.3-6.9)$ & 0.004 & $0.79(0.65-0.95)$ & $4.11(0.847)$ & 0.63 & $0.23(0.09-0.33 ; \leq 6.4)$ \\
\hline
\end{tabular}


AUC, Area Under the Receiver Operating Characteristic (ROC) curve. Hb, Hemoglobin; H-L, Hosmer-Lemeshow goodness of fit test; IAP, Intra-Abdominal Pressure (mmHg); OR, Odds Ratio; PT, Prothrombin Time; PTT, Partial Thromboplastin Time.

Descriptive data are shown as median with the $\mathrm{P}_{25}-\mathrm{P}_{75}$ between brackets or as number with the percentage between brackets.

P-values are calculated using a Mann-Whitney U-test.

${ }^{A}$ Data were missing for 120 patients at the ED recording (106 in the $\leq 20 \mathrm{mmHg}$ group and 14 in the $>20 \mathrm{mmHg}$ group) and for 78 patients at the 6 hours recording (76 versus 2); ${ }^{\mathrm{B}}$ Data were missing for 509 patients at the ED recording (461 versus 48 ) and for 507 patients at the 6 hours recording (464 versus 43); ${ }^{\mathrm{C}}$ Data were missing for 267 patients at the ED recording (252 versus 15) and for 204 patients at the 6 hours recording (203 versus 1); ${ }^{\mathrm{D} D a t a}$ were missing for 262 patients at the ED recording (247 versus 15) and for 201 patients at the 6 hours recording (199 versus 2); ${ }^{\mathrm{E}}$ Data were missing for 285 patients at the ED recording (266 versus 19) and for 265 patients at the 6 hours recording (257 versus 8 ); ${ }^{\mathrm{F}} \mathrm{Data}$ were missing for 214 patients at the 6 hours recording (213 versus 1); ${ }^{\mathrm{G}}$ Data were missing for 212 patients at the 6 hours recording (211 versus $1)$.

Odds Ratios are determined using a binary logistic regression and are given with the 95\% confidence interval (CI) between brackets. The H-L statistic is given with the p-value between brackets. Statistically significant OR's and H-L values are shown in boldface. The Youden Index is shown with the $95 \%$ CI and the threshold value between brackets.

N.D., not determined, as SPSS was unable to compute these values. 
Table 3 - Resuscitation fluid given at the emergency department or in the first 24 hours of admission, separated for the groups with an

\section{IAP $\leq 20 \mathrm{mmHg}$ and $>20 \mathrm{mmHg}$}

\begin{tabular}{|c|c|c|c|c|c|c|c|c|}
\hline Variable & $\begin{array}{l}\text { Overall } \\
(\mathrm{N}=567)\end{array}$ & $\begin{array}{l}\text { IAP } \leq 20 \\
(N=509)\end{array}$ & $\begin{array}{c}\text { IAP > 20 } \\
(\mathrm{N}=58)\end{array}$ & P-value & $\begin{array}{c}\text { OR } \\
(95 \% \mathrm{CI})\end{array}$ & $\begin{array}{c}\text { H-L Test } \\
\text { (Chi-square) }\end{array}$ & $\mathbf{A U C}$ & $\begin{array}{c}\text { Youden Index } \\
(95 \% \mathrm{CI} \text {; threshold) }\end{array}$ \\
\hline Volume given at ED (L) & $1.5(0.4-2.5)$ & $1.5(0.2-2.5)$ & $2.4(1.0-3.5)$ & 0.001 & $1.04(0.97-1.11)$ & $11.92(0.064)$ & 0.63 & $0.24(0.10-0.33 ;>1.5)$ \\
\hline Volume given $<24 \mathrm{~h}(\mathrm{~L})^{\mathrm{A}}$ & $6.0(4.3-8.5)$ & $6.0(4.0-8.2)$ & $9.5(6.3-13.3)$ & $<0.001$ & $1.17(1.11-1.24)$ & $11.79(0.161)$ & 0.72 & $0.41(0.22-0.58 ;>8.3)$ \\
\hline Volume Crystalloids given $<24 \mathrm{~h}(\mathrm{~L})^{\mathrm{B}}$ & $4.5(3.0-6.0)$ & $4.2(3.0-6.0)$ & $6.0(4.3-7.6)$ & $<0.001$ & $1.20(1.11-1.30)$ & $11.93(0.154)$ & 0.67 & $0.33(0.17-0.42 ;>5.2)$ \\
\hline Volume Colloids given $<24 \mathrm{~h}(\mathrm{~L})^{\mathrm{C}}$ & $1.5(0.5-3.0)$ & $1.5(0.0-2.9)$ & $2.5(1.5-5.0)$ & $<0.001$ & $1.21(1.11-1.32)$ & $19.23(0.007)$ & 0.69 & $0.33(0.22-0.39 ;>1.2)$ \\
\hline Packed Red Cells given $<24 \mathrm{~h}\left(\right.$ Units) ${ }^{\mathrm{B}}$ & $2(0-10)$ & $2(0-8)$ & $17(8-33)$ & $<0.001$ & $1.08(1.06-1.10)$ & $22.90(<0.001)$ & 0.84 & $0.57(0.47-0.66 ;>6)$ \\
\hline
\end{tabular}

AUC, Area Under the Receiver Operating Characteristic (ROC) curve. H-L, Hosmer-Lemeshow goodness of fit test; IAP, Intra-Abdominal

Pressure (mmHg); ED, Emergency Department; OR, Odds Ratio.

Descriptive data are shown as median with the $\mathrm{P}_{25}-\mathrm{P}_{75}$ between brackets or as number with the percentage between brackets.

P-values are calculated using a Mann-Whitney U-test.

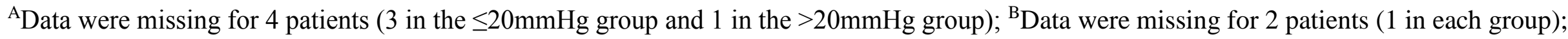

${ }^{\mathrm{C}}$ Data were missing for 3 patients ( 3 in the $\leq 20 \mathrm{mmHg}$ group and 0 in the $>20 \mathrm{mmHg}$ group). 
Odds Ratios are determined using a binary logistic regression and are given with the $95 \%$ confidence interval (CI) between brackets. The H-L statistic is given with the p-value between brackets. Statistically significant OR's and H-L values are shown in boldface. The Youden Index is shown with the $95 \% \mathrm{CI}$ and the threshold value between brackets. 
Table 4 - Mortality, length of stay at ICU and hospital separated for the groups with an IAP $\leq 20 \mathrm{mmHg}$ and $>20 \mathrm{mmHg}$

\begin{tabular}{lcccc}
\hline Variable & Overall & IAP $\leq \mathbf{2 0}$ & IAP $>\mathbf{2 0}$ & P-value \\
& $\mathbf{( N = 5 6 7 )}$ & $\mathbf{( N = 5 0 9 )}$ & $\mathbf{( N = 5 8 )}$ & \\
\hline Mortality & $77(13.6 \%)$ & $62(12.2 \%)$ & $15(25.9 \%)$ & $0.012^{\mathrm{A}}$ \\
LOS ICU (days) & $2(0-6)$ & $1(0-4)$ & $15(8-27)$ & $<0.001$ \\
LOS Hospital (days) & $10(6-20)$ & $9(6-17)$ & $44(15-65)$ & $<0.001$ \\
\hline
\end{tabular}

IAP, Intra-Abdominal Pressure (mmHg); LOS, Length of Stay.

Data are shown as median with the $\mathrm{P}_{25}-\mathrm{P}_{75}$ between brackets or as number with the percentage between brackets.

P-values are calculated using Mann-Whitney U-test and AFisher's exact test. 
Figure 1. Association between closure timing, intra-abdominal hypertension and mortality in patients after trauma laparotomy

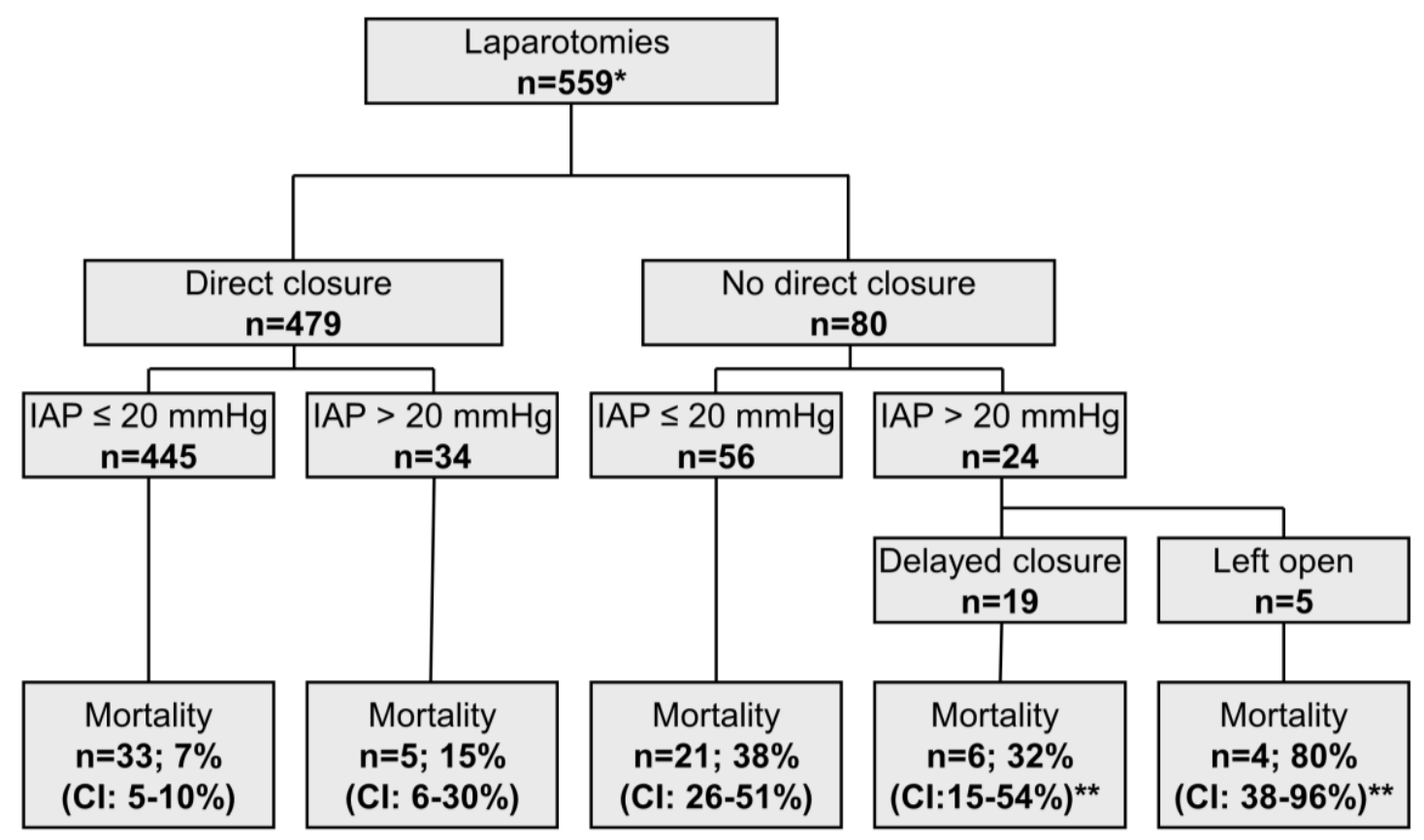

IAH, Intra-Abdominal Hypertension;

Results are shown as numbers with percentage (95\% Confidence Interval, 95\% CI)

* Of 8 additional patients who underwent trauma laparotomy no data were available regarding the closure technique. They are therefore not included in this flowchart.

**Not significant $(\mathrm{p}=0.122)$. 


\section{References}

1. CDC WISQARS: web-based injury statistics query and reporting system. Available at www.cdc.gov/injury/wisqars/LeadingCauses.html Accessed March 5, 2013.

2. Nishijima DK, Simel DL, Wisner DH, Holmes JF. Does this adult patient have a blunt intra-abdominal injury? JAMA. 2012;307(14):1517-27.

3. Ertel W, Oberholzer A, Platz A, Stocker R, Trentz O. Incidence and clinical pattern of the abdominal compartment syndrome after "damage-control" laparotomy in 311 patients with severe abdominal and/or pelvic trauma. Crit Care Med. 2000;28(6):1747-1753.

4. Offner PJ, de Souza AL, Moore EE, Biffl WL, Franciose RJ, Johnson JL, Burch JM. Avoidance of abdominal compartment syndrome in damage-control laparotomy after trauma. Arch Surg. 2001;136(6):676-681.

5. Moore AF, Hargest R, Martin M, Delicata RJ. Intra-abdominal hypertension and the abdominal compartment syndrome. Br J Surg. 2004;91(9):1102-1110.

6. Malbrain ML, Cheatham ML, Kirkpatrick A, Sugrue M, Parr M, De Waele J, Balogh Z, Leppaniemi A, Olvera C, Ivatury R, et al. Results from the International Conference of Experts on Intra-abdominal Hypertension and Abdominal Compartment Syndrome. I. Definitions. Intensive Care Med. 2006;32(11):1722-1732.

7. De Laet IE, Ravyts M, Vidts W, Valk J, De Waele JJ, Malbrain ML. Current insights in intra-abdominal hypertension and abdominal compartment syndrome: open the abdomen and keep it open! Langenbecks Arch Surg. 2008;393(6):833-847.

8. Kirkpatrick AW, Roberts DJ, De Waele J, Jaeschke R, Malbrain ML, De Keulenaer B, Duchesne J, Bjorck M, Leppaniemi A, Ejike JC, et al. Intra-abdominal hypertension and the abdominal compartment syndrome: updated consensus definitions and clinical 
practice guidelines from the World Society of the Abdominal Compartment Syndrome. Intensive Care Med. 2013;39(7):1190-1206.

9. Scott BG, Welsh FJ, Pham HQ, Carrick MM, Liscum KR, Granchi TS, Wall MJ, Jr., Mattox KL, Hirshberg A. Early aggressive closure of the open abdomen. J Trauma. 2006;60(1):17-22.

10. Cheatham ML, Safcsak K, Llerena LE, Morrow CE, Jr., Block EF. Long-term physical, mental, and functional consequences of abdominal decompression. $J$ Trauma. 2004;56(2):237-241; discussion 241-232.

11. Hatch QM, Osterhout LM, Podbielski J, Kozar RA, Wade CE, Holcomb JB, Cotton BA. Impact of closure at the first take back: complication burden and potential overutilization of damage control laparotomy. J Trauma. 2011;71(6):1503-1511.

12. Montalvo JA, Acosta JA, Rodriguez P, Alejandro K, Sarraga A. Surgical complications and causes of death in trauma patients that require temporary abdominal closure. Am Surg. 2005;71(3):219-224.

13. Shapiro MB, Jenkins DH, Schwab CW, Rotondo MF. Damage control: collective review. J Trauma. 2000;49(5):969-978.

14. Liverpool Hospital, Sydney. Available at www.trauma.org Accessed March 5, 2013.

15. South Western Area Health Service. Available at http://www.sswahs.nsw.gov.au/ Accessed March 5, 2013.

16. Niles SE, McLaughlin DF, Perkins JG, Wade CE, Li Y, Spinella PC, Holcomb JB. Increased mortality associated with the early coagulopathy of trauma in combat casualties. J Trauma. 2008;64(6):1459-1463; discussion 1463-1455.

17. Madigan MC, Kemp CD, Johnson JC, Cotton BA. Secondary abdominal compartment syndrome after severe extremity injury: are early, aggressive fluid resuscitation strategies to blame? J Trauma. 2008;64(2):280-285. 
18. Balogh Z, McKinley BA, Holcomb JB, Miller CC, Cocanour CS, Kozar RA, Valdivia A, Ware DN, Moore FA. Both primary and secondary abdominal compartment syndrome can be predicted early and are harbingers of multiple organ failure. $J$ Trauma. 2003;54(5):848-859; discussion 859-861.

19. Malbrain ML, Chiumello D, Pelosi P, Bihari D, Innes R, Ranieri VM, Del Turco M, Wilmer A, Brienza N, Malcangi V, et al. Incidence and prognosis of intraabdominal hypertension in a mixed population of critically ill patients: a multiple-center epidemiological study. Crit Care Med. 2005;33(2):315-322.

20. Neal MD, Hoffman MK, Cuschieri J, Minei JP, Maier RV, Harbrecht BG, Billiar TR, Peitzman AB, Moore EE, Cohen MJ, et al. Crystalloid to packed red blood cell transfusion ratio in the massively transfused patient: when a little goes a long way. $J$ Trauma Acute Care Surg. 2012;72(4):892-898.

21. Annane D, Siami S, Jaber S, Martin C, Elatrous S, Declere AD, Preiser JC, Outin H, Troche G, Charpentier C, et al. Effects of fluid resuscitation with colloids vs crystalloids on mortality in critically ill patients presenting with hypovolemic shock: the CRISTAL randomized trial. JAMA. 2013;310(17):1809-1817.

22. Myburgh JA, Finfer S, Bellomo R, Billot L, Cass A, Gattas D, Glass P, Lipman J, Liu B, McArthur C, et al. Hydroxyethyl starch or saline for fluid resuscitation in intensive care. N Engl J Med. 2012;367(20):1901-1911.

23. Perner A, Haase N, Guttormsen AB, Tenhunen J, Klemenzson G, Aneman A, Madsen KR, Moller MH, Elkjaer JM, Poulsen LM, et al. Hydroxyethyl starch 130/0.42 versus Ringer's acetate in severe sepsis. N Engl J Med. 2012;367(2):124-134.

24. Miller RS, Morris JA, Jr., Diaz JJ, Jr., Herring MB, May AK. Complications after 344 damage-control open celiotomies. J Trauma. 2005;59(6):1365-1371; discussion 13711364. 
25. Dubose JJ, Scalea TM, Holcomb JB, Shrestha B, Okoye O, Inaba K, Bee TK, Fabian TC, Whelan J, Ivatury RR, et al. Open abdominal management after damage-control laparotomy for trauma: a prospective observational American Association for the Surgery of Trauma multicenter study. J Trauma Acute Care Surg. 2013;74(1):113120; discussion 1120-1122.

26. Balentine C, Subramanian A, Palacio CH, Sansgiry S, Berger DH, Awad SS. AVAS Best Clinical Resident Award (Tied): management and outcomes of the open abdomen in nontrauma patients. Am J Surg. 2009;198(5):588-592.

27. Demetriades D. Total management of the open abdomen. Int Wound J. 2012;9 Suppl 1:17-24. 